ISO 9001:2008 Certified

International Journal of Engineering and Innovative Technology (IJEIT)

Volume 10, Issue 7, January 2021

\title{
Topology Optimization of a Swingarm used in a Hyperloop Pod
}

\author{
Swarali Govilkar, Saurav Patwardhan \\ Department of Mechanical Engineering, College of Engineering, Pune, India
}

\begin{abstract}
This paper aims to conduct topology optimization of a swingarm on a student designed prototype of a hyper loop pod via Finite Element Analysis. A hyper loop pod needs to be lightweight to achieve high speeds. As such it becomes important to analyze each component and reduce weight where possible while maintaining the necessary strength and safety constraints. The suspension swingarm is a critical member of the structural chassis transferring forces to the chassis from the wheels. The part was modeled in Solid Works and the FEA was conducted using Ansys Academic. A total of three iterations were modeled and analyzed with a goal of reducing mass and ensuring efficient stress distribution in the swingarm. Modal analysis from Ansys is used to find out the natural frequency of the swingarm and it is compared with the predicted operating frequency of the system. The result of this research is a well optimized design of the swingarm delivering the requisite strength as well as a 40 percent mass reduction.
\end{abstract}

Index Terms-Hyperloop, Topology optimization, Vibrational analysis, Finite element analysis, Swingarm, Suspension.

\section{INTRODUCTION}

A swingarm, also known as a swing fork or a pivoted fork is a component of suspension systems. It is mostly used in motorbikes. It is free to pivot at one end to absorb imperfections on the surface on which the vehicle travels.

A Hyperloop Pod is a small pod running at very high speeds on an I-rail inside a vacuum tube. The hyper loop concept was conceptualized by Elon Musk in 2013 and since then various teams around the world have designed prototypes of the same.

A simple swingarm has been designed for the suspension of a proposed hyper loop pod. It has been designed keeping in mind the space and shape constraints primarily. It houses a wheel powered by a $2.5 \mathrm{~kW}$ BLDC motor. Its upper end is attached via mounts to the main structural frame of the pod. Its lower end is attached to a spring-damper system which absorbs the shocks. The pod weighs roughly 180 kilograms and is expected to run at speeds upwards of $50 \mathrm{~m} / \mathrm{s}$. One of the objectives of this paper is to analyze the loads coming on the swingarm and ensure the safety of the design.

As the primary goal of the hyperloop concept is to achieve very high speeds, weight is an important design consideration and weight reduction becomes an essential part of the process. Hence, a need for topology optimization with a goal of mass reduction was felt. Optimization of the topology is a mathematical process which optimizes the material layout for a given set of loads, border conditions and constraints within a design space in order to maximize system efficiency.

Manuscript received: 19 December 2020

Manuscript received in revised form: 16 January 2021

Manuscript accepted: 01 February 2021

Manuscript Available online: 15 February 2021
For estimation and calculation purposes, Finite Element Analysis is used. The expected result of this optimization is to get a lightweight, strong and safe design with an efficient stress distribution by removal of the mass which is under little to no stress.

Modal analysis of each iteration is also carried out to find out the natural frequency of the swingarm and its first 10 modes. It is expected that the natural frequencies of the swingarm be far away from the operational frequencies of the system to avoid resonance and subsequent deformation. The pod is to run on an I-rail made of Aluminum with a good, smooth surface and with no unexpected variations on its surface. Hence, the operating frequencies of the pod are predicted to range from $5 \mathrm{~Hz}$ to $25 \mathrm{~Hz}$ for its sprung mass.

The original design and three further iterations are compared with each other on the basis of mass, maximum deformation, maximum Von Mises stress, maximum Factor of Safety (FOS) and natural frequency. The optimal design is selected for use based on the above criteria.

During the design of the Hyperloop Pod, cost is a secondary consideration behind performance. As such, each part needs to be optimized keeping weight in mind despite an increase in production cost.

Thus, the primary purpose of this research was the development of a lightweight and strong suspension swingarm with more even stress distribution to enable better load transfer and facilitate higher speeds for the pod.

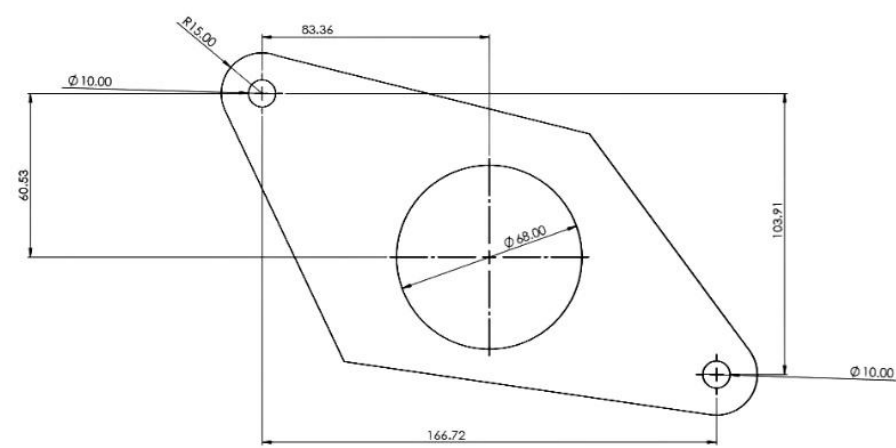

Fig.1. Part drawing of the original design of the swingarm (All dimensions are in $\mathbf{m m}$ )

\section{LITERATURE REVIEW}

Topology optimization has been well researched in the past few decades since M.P. Bendsøe and N. Kikuchi [1] published their work. It has rapidly developed into one of the most widely used techniques in engineering, further facilitated by the wide availability of FEA software's and inexpensive computing power. Further advances in structural 


\section{ISSN: 2277-3754 \\ ISO 9001:2008 Certified \\ International Journal of Engineering and Innovative Technology (IJEIT) \\ Volume 10, Issue 7, January 2021}

topology optimization have been realized after it was looked at as a material distribution problem [2] and an interactive system for topology optimization and design was developed by Olhoff et al [3]. Mass reduction using topology optimization for high performance vehicle components has been well documented by S.M. Edmund, R. Arora [4] (optimization of a three stage transmission); P. Wu et al [5]. (Design of an automotive engine bracket). J Brennan, K Hayes [6] published a review of the applications of Topology Optimization for Automotive Design detailing structural analysis and design considerations in industrial applications using Altair Optistruct. A recent study of stress based topology optimization was carried out by Picelli et al [7]. Stress minimization, stress constraints and multiple load cases and stress criteria were considered and it was found that the level set method produces efficient solutions with smooth boundaries. Federico Ballo et al. have minimized the mass of a racing motorcycle wheel using optimized structural layouts [8]. Harald Fredricson published a comprehensive literature review of topology optimization applications in the vehicle industry. The major focus is on applications for vehicle body structures [9]. There is plenty of evidence to suggest that Structural Topology Optimization is a viable solution for the mass reduction problem faced by Hyperloop Pod designers. The main premise is a pod which travels through a vacuum tube at a very high speed as a new means of land transportation. Various design teams and companies have sprung up since then working on their own models of Hyperloop pods. The suspension in a Hyperloop Pod can take the conventional mechanical spring damper route or the electromagnetic route. KK Ivanovich, KK Konstantinovich [10] has analyzed some electromagnetic suspension systems for Hyperloop pods. Both these systems need the suspension links to transfer large forces effectively to the chassis and hence their proper design becomes crucial. At the same time, the need for high top speeds and acceleration figures means that the designs need to be light and redundant mass with little to no stress needs to be removed. This is the primary motivation behind the optimization of the proposed swingarm design. Suspension swingarms have been well studied in bikes. Atishay Jain's work in developing a castable swingarm design and reducing the design iteration cycle time is done through a conceptual approach instead of the conventional experience based approach [11]. Comprehensive design research by $\mathrm{S}$. Cassani and A. Mancuso has resulted in the shape optimization of a pipe-based swingarm for a motorbike [12]. The new shape was extensively tested to verify their simulations and further prove the validity of shape optimization as a design tool. They analyzed one sided suspension swingarms. Solid Works was used to draw the models and the calculation analysis was done using MATLAB. Vibrational analysis was done using FEM software Patran-Nastran. The work towards the static-vibrational design of an automobile bonnet and its strengthening frame which is topologically optimized is done both experimentally and theoretically. This provides a useful comparison between practical and analytical results for this method. The operating frequency of a Hyperloop pod has not been well researched. However the weight of the proposed pod $(180 \mathrm{~kg})$ and the speeds (upwards of $40 \mathrm{~m} / \mathrm{s}$ ) are very comparable to high performance motorcycles. The frequency of operation of motorcycles is a well researched area and the works of A. Zanarini, E. Brugnoni [14] show that they will not exceed $25 \mathrm{~Hz}$. This means that the above referenced results can be duly taken into consideration for our purpose. After a survey of the existing literature, it was observed that research pertaining to components on Hyperloop pods is negligible. Topology optimization has been established as a widely used design tool by engineers since a long time and is applicable to a variety of components. However, traditional research has focused more on static components than dynamic ones. Modal analysis of components to find out the natural frequency and its relationship with the operating frequency has been previously done but formal research regarding the same is hard to come.

\section{MATHEMATICAL CALCULATIONS}

The various reaction forces and moments acting on the swing arm are calculated analytically. These are used as inputs to analyze the swingarm using Ansys Academic.

\section{A) From the wheel}

1) Normal reaction from the wheel: The wheels over an upward reaction to the weight of the pod. This reaction acts as an upward force on the upper inner half of the slot for the ball bearing.

Total weight of the pod $=180 \mathrm{~kg}$

Total downward force on wheels $=(180 * 9.81) \mathrm{N}=1765.8 \mathrm{~N}$ Downward force on each wheel $=(1765.8 / 4) \mathrm{N}=441.45 \mathrm{~N}$ Upward reaction of wheel $=441.45 \mathrm{~N}$

2) Weight transfer: Weight transfer has to be accounted for because it is the extra force that acts on the wheels when the hyper loop pod accelerates or decelerates. Here the scenario of maximum deceleration is considered. This also acts as an upward force on the upper inner half of the slot for the ball bearing.

$$
\begin{aligned}
& \text { Where, } \mathrm{W}=(\mathrm{a} * \mathrm{~h} * \mathrm{~m}) / \mathrm{w} \\
& \mathrm{W}=\text { weight transfer } \\
& \mathrm{a}=\text { longitudinal acceleration }=9.81 \mathrm{~m} / \mathrm{s} 2 \\
& \mathrm{~h}=\text { center of mass height }=400 \mathrm{~mm} \\
& \mathrm{~W}=\text { wheelbase }=891.36 \mathrm{~mm} \\
& \mathrm{~m}=\text { total mass of the pod }=180 \mathrm{~kg} \\
& \text { Calculating, } \quad \Delta \mathrm{W}=792.41 \mathrm{~N}
\end{aligned}
$$

However, this weight transfer is for the entire axle and is calculated when the deceleration is maximum. $\Delta \mathrm{w}($ for 1 wheel $)=(792.41 / 2) \mathrm{N}=396.2 \mathrm{~N}$

Total force $=\mathrm{FW}=(441.45+396.2) \mathrm{N}=837.65 \mathrm{~N}$

3) There is a slight horizontal offset between the swingarm and the wheel. Hence, we need to consider a moment in order to transfer the forces to the swingarm. $\mathrm{M}_{\mathrm{w}}=\mathrm{F}_{\mathrm{w}} * \mathrm{r}_{\mathrm{w}}$

$$
\begin{aligned}
& \mathrm{Fw}_{\mathrm{w}}=837.65 \mathrm{~N} \\
& \mathrm{r}_{\mathrm{w}}=14.5 \mathrm{~mm} \\
& \mathrm{M}_{\mathrm{w}}=12.15 \mathrm{Nm}
\end{aligned}
$$




\section{ISO 9001:2008 Certified \\ International Journal of Engineering and Innovative Technology (IJEIT) \\ Volume 10, Issue 7, January 2021}

\section{B) From the spring}

If the pod encounters irregularities or bumps during its run, the spring attached to the swingarm would compress. This gives an upward reaction force on the swingarm. The spring is attached at an angle of $60^{\circ}$ to the horizontal. Hence the reaction force has 2 components- horizontal (Rh) and vertical $(\mathrm{Rv})$. The total force in the spring is $565 \mathrm{~N}$.

1) $\mathrm{R}_{\mathrm{h}}=565 \cos 600=282.5 \mathrm{~N}$

2) $\mathrm{R}_{\mathrm{v}}=565 \sin 600=489.3 \mathrm{~N}$

Moments due to spring: The spring is attached at a certain distance away from the swingarm. In order to transfer the reactions to the swingarm, moments are considered.

$$
\text { 3) } \begin{aligned}
& \mathrm{Mh}=\mathrm{R}_{\mathrm{h}} * \mathrm{r}_{\mathrm{h}}=15 \mathrm{~mm} \\
& \mathrm{M}_{\mathrm{h}}=4.2 \mathrm{Nm} \\
& \text { 4) } \mathrm{M}_{\mathrm{v}}=\mathrm{Rv} * \mathrm{rv} \\
& \mathrm{r}_{\mathrm{v}}=15 \mathrm{~mm} \\
& \mathrm{M}_{\mathrm{v}}=7.4 \mathrm{Nm}
\end{aligned}
$$

\section{C) Torsion due to shaft of motor}

Torsion is experienced by the swingarm because of the shaft of the motor (which powers the wheels).

$$
\begin{aligned}
& \mathrm{T}=\mathrm{P} / \mathrm{n} \\
& \mathrm{P}=\text { Power of BLDC (Brushless DC Motor) }=2500 \mathrm{~W} \\
& \mathrm{rpm}=2000 \\
& \mathrm{n}=\text { frequency of rotation }=\mathrm{rpm} *(2 \pi / 60)=209.44 \mathrm{rad} / \mathrm{s} \\
& \mathrm{T}=12 \mathrm{Nm}
\end{aligned}
$$

According to the SpaceX specifications for the I-rail track, a small step of $1 \mathrm{~mm}$ may be between segments of the track which have been joined together. No other bumps or undulations are present on the track and do not need to be separately considered.

\section{MATERIAL SELECTION}

Aluminum alloys are light in weight and have considerable strength which is one of the primary requirements of any hyperloop part. They have potential for better material layout. They are also profitable as they reduce the design iteration time. Based on these observations, an aluminum alloy - Al 6061 T6 was selected. The properties of the same are tabulated as shown in Table 1.

Table 1. Material properties

\begin{tabular}{|c|c|c|}
\hline Property & Aluminum Alloy & Unit \\
\hline Density & 2770 & $\mathrm{~kg} / \mathrm{m}^{3}$ \\
\hline Young's Modulus & 71000 & $\mathrm{MPa}$ \\
\hline Poisson's Ratio & 0.33 & $\mathrm{MPa}$ \\
\hline Bulk Modulus & 69608 & $\mathrm{MPa}$ \\
\hline Yield Strength & 26692 & $\mathrm{MPa}$ \\
\hline $\begin{array}{c}\text { Tensile Ultimate } \\
\text { Strength }\end{array}$ & 280 & \\
\hline
\end{tabular}

\section{MODELLING AND ANALYSIS}

1. Primary considerations for design were space available for mounting it appropriately on the hyperloop chassis.

2 . The solid modeling of the part was done using Solid works 2018.

3. The analysis has been conducted using Ansys Academic 2020. The part, in each iteration, was tested using structural analysis for stress, deformation and factor of safety. The solution thus obtained when each test was run was used to make a comparative study among the iterations. Additionally, vibrational analysis was done on the swingarm.

4. The material applied was Al $6061 \mathrm{~T} 6$.

5. Excessive stress and subsequent deformation of the swingarm may be caused if the operating frequency of the pod suspension and the natural frequency of the swingarm match and result in resonance. Thus, a need was felt to check the natural frequency of our design iterations and ensure it is far away from the operating frequency of the pod. A modal analysis was carried out in Ansys for each iteration. No default settings were adjusted. The mesh parameters are the same as those used for the structural analysis.

Boundary conditions that were used while applying FEA:

\begin{tabular}{|c|c|c|c|}
\hline \multicolumn{4}{|c|}{ Details of "Mesh" } \\
\hline \multirow[t]{4}{*}{$\nabla$} & \multicolumn{2}{|l|}{ Defaults } & 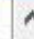 \\
\hline & Physics Preference & Mechanical & \\
\hline & Element Order & Program Controlled & \\
\hline & $\square$ Element Size & $4.0 \mathrm{~mm}$ & \\
\hline \multirow[t]{8}{*}{$\nabla$} & \multicolumn{2}{|l|}{ Sizing } & \\
\hline & Use Adaptive Sizi... & Yes & \\
\hline & Resolution & Default (2) & \\
\hline & Mesh Defeaturing & Yes & \\
\hline & $\square$ Defeature Size & Default & \\
\hline & Transition & Fast & \\
\hline & Span Angle Center & Coarse & \\
\hline & Initial Size Seed & Assembly & \\
\hline
\end{tabular}
The upper hole which is used to mount the swingarm to the main chassis has been considered as a fixed support. No other restrictions have been imposed on the motion of the part.

Mesh Parameters: The geometry of the built part is divided into basic elements that are used as disagreeable local approximations for the larger domain when the part is checked with Ansys Academic. The mesh affects simulation precision, convergence and speed. The mesh settings used are as shown in Fig 2.

\section{Loads on the swingarm}

Fig 2: Mesh settings

a. The moment caused by the spring which is offset is equal to the vector addition of the moments caused due to the horizontal and vertical components of the spring force.

b.It is equal to $8508.8 \mathrm{~N} \mathrm{~mm}$

c. The vertical force due to the spring has been rounded off to $500 \mathrm{~N}$.

d.The horizontal force due to the spring can be safely rounded to $300 \mathrm{~N}$ for analysis.

e. The total vertical reaction force from the wheel is a combination of the weight of the pod as well as the weight transfer during maximum deceleration. This has been applied as $850 \mathrm{~N}$.

$\mathrm{f}$. The torsion from the motor is $12000 \mathrm{~N} \mathrm{~mm}$. g. The moment from the vertical force from the offset wheel is $12150 \mathrm{~N} \mathrm{~mm}$ in the analysis. 


\section{ISSN: 2277-3754 \\ ISO 9001:2008 Certified \\ International Journal of Engineering and Innovative Technology (IJEIT) \\ Volume 10, Issue 7, January 2021}

\section{ITERATIONS}

Original Design: The original design of the swingarm, as shown in Fig 3, was modeled using Solid Works 2018. This is referred to as the original design in this research. The mass of the part was evaluated using the 'Mass Properties' feature in SolidWorks. Mass of the original design $=585.143$ gram .

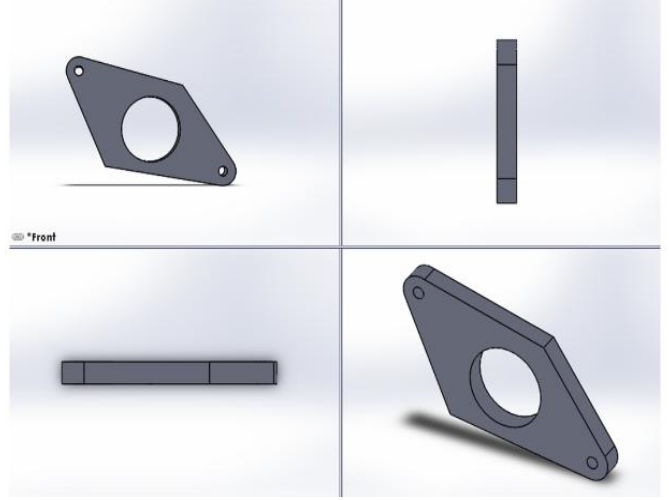

Fig 3: Solid Works model for Original Design

Analysis was done using the Static Structural feature in Ansys Academic. The maximum Equivalent (von-Mises) Stress was $39.438 \mathrm{MPa}$. The maximum total deformation was $0.112 \mathrm{~mm}$. A relatively high stress region is seen only near the slot where the swingarm is connected to the chassis. This is illustrated in Fig 4.

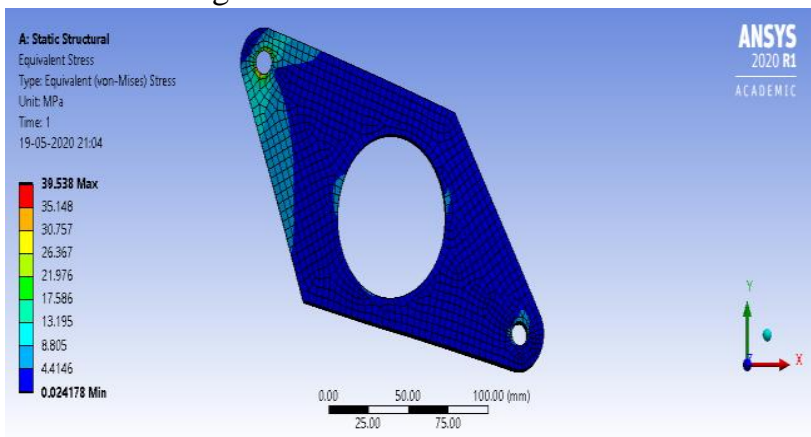

Fig 4: Equivalent Stress Plot for Original Design

Vibrational analysis of the original design was done using the Modal Analysis system in Ansys Academic and the first natural frequency was found to be $331.34 \mathrm{~Hz}$. Topology optimization was done for the design. The results obtained are shown in Fig 5.

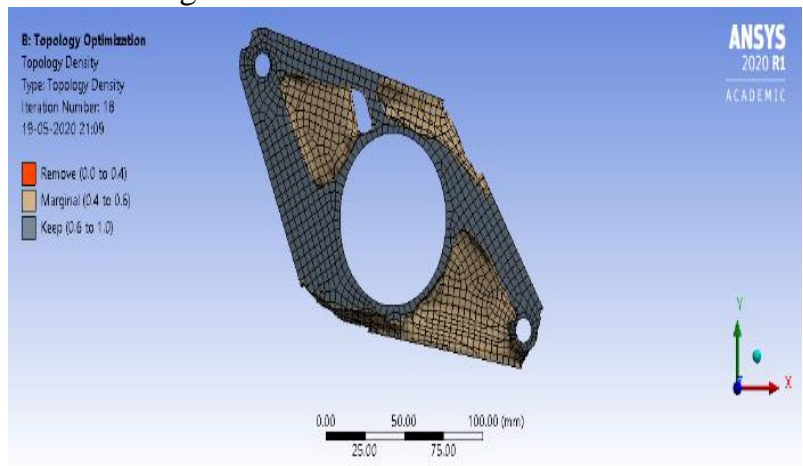

Fig 5: Topology Optimization for Original Design

Iteration 1: The results from the topology optimization were interpreted. The original model had negligible stress in the region between the circular holes. Also, the width of the swing arm was more than necessary. Hence, the width of the model was reduced by modifying the model in Solid Works as shown in Fig 6. The mass of the model for iteration 1 was 374.089 gram.

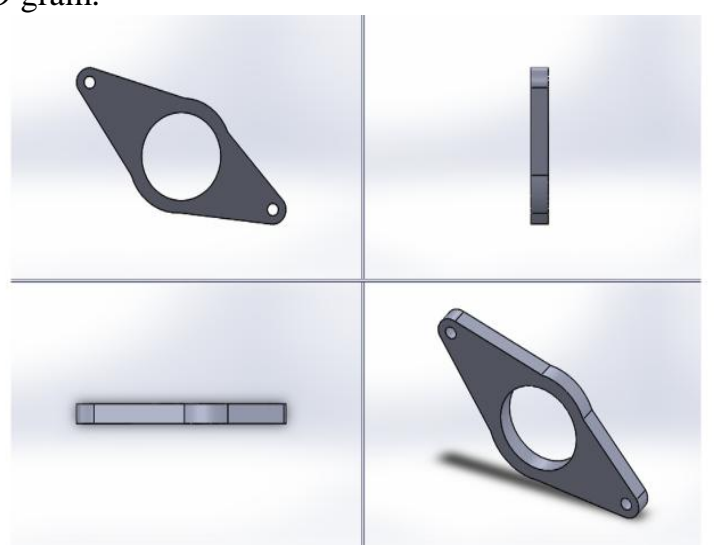

Fig 6: Solid Works model for Iteration 1

Again FEA was performed on this model. The maximum Equivalent (von-Mises) Stress was obtained as 53.077 $\mathrm{MPa}$ and the maximum deformation was $0.213 \mathrm{~mm}$. This is shown in Fig 7.

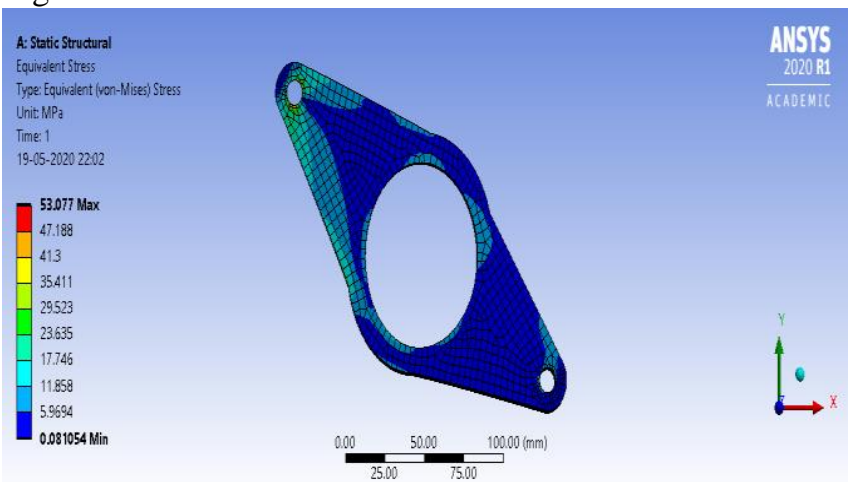

Fig 7: Equivalent Stress Plot for Iteration 1

First natural frequency of $289.46 \mathrm{~Hz}$ was obtained from vibrational analysis. Topology optimization was done again. The results strongly pointed towards reducing the material in the region between the holes as shown in Fig 8.

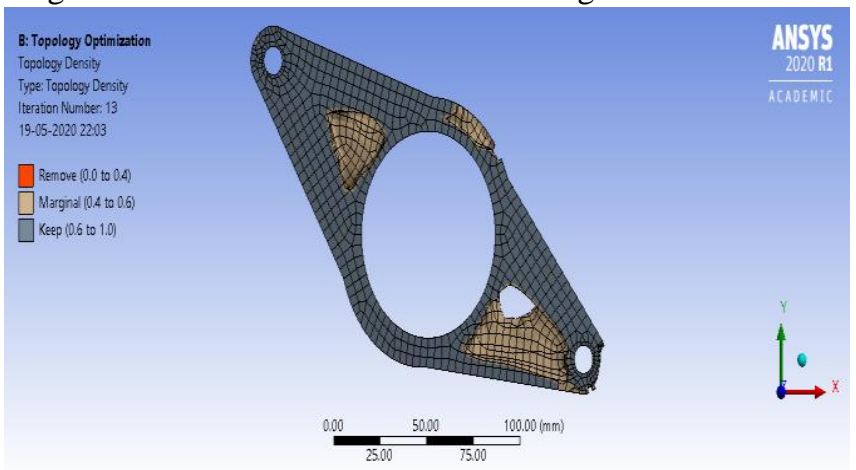

Fig 8: Topology Optimization for Iteration 1

Iteration 2: The results obtained after topology optimization were used as guidelines. Accordingly two slots were cut. The edges of these slots were made parallel to the edges of the swingarm. The corners of these slots were fleeted to avoid stress concentration. The width of the model, however, was increased a little to avoid failure due to very thin cross section as illustrated in Fig 9. The mass of this model was 400.964 gram. 
ISSN: 2277-3754

ISO 9001:2008 Certified

International Journal of Engineering and Innovative Technology (IJEIT)

Volume 10, Issue 7, January 2021

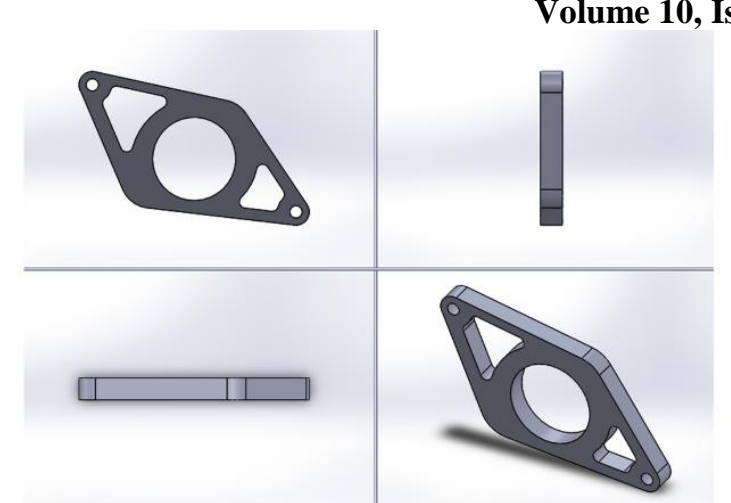

Fig 9: Solid Works model for Iteration 2

The maximum Equivalent (von-Mises) Stress was 62.239 $\mathrm{MPa}$. The maximum deformation was $0.329 \mathrm{~mm}$, shown in Fig 10.

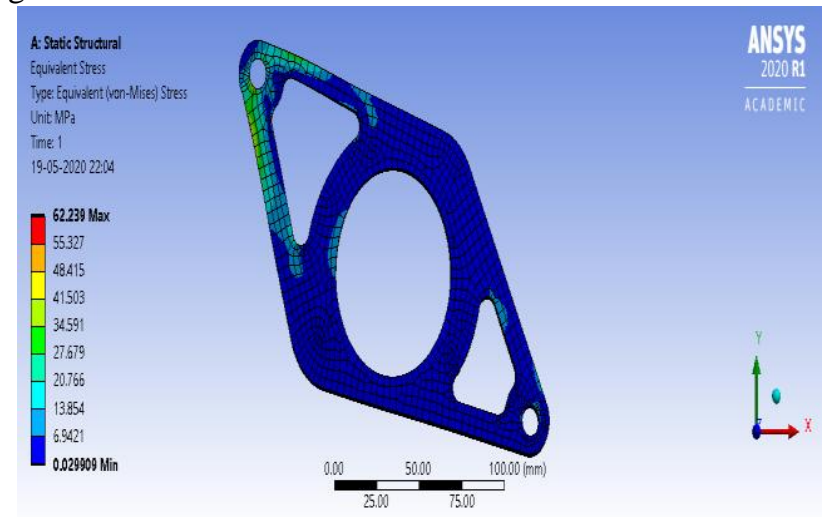

Fig 10: Equivalent Stress Plot for Iteration 2

Vibrational analysis was done and the first natural frequency obtained for this iteration was $315.36 \mathrm{~Hz}$. Topology optimization was done again. The stresses around the central circular slot were very low and material in that region could be removed. This is shown in Fig 11.

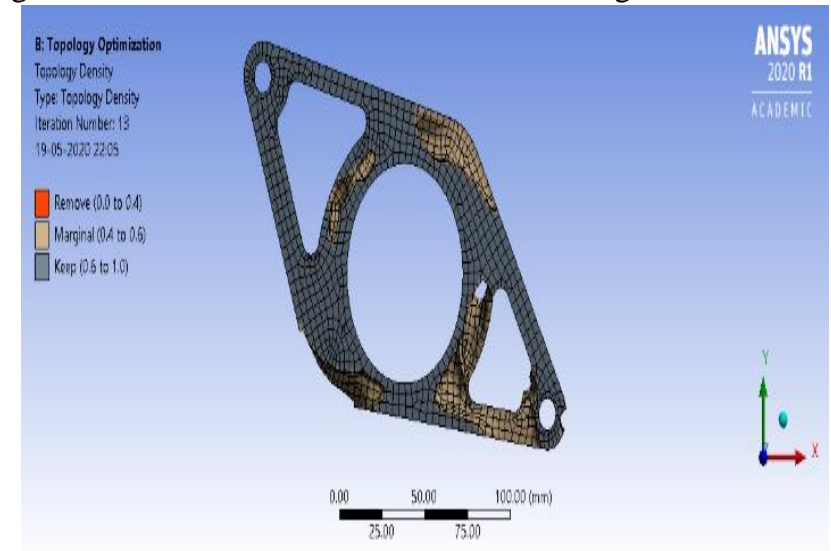

Fig 11: Topology Optimization for Iteration 2

Iteration 3: The two approaches adopted in iteration 1 (reduction of width of the springarm) and iteration 2 (creation of slots) were analyzed. Using the results from topology optimization as guidelines both these approaches were clubbed and the model was modified accordingly. The width of the swingarm was reduced and the region around the central circular hole was made curved as is seen in Fig 12. The mass reduced to a considerable extent. It was 345.826 gram.

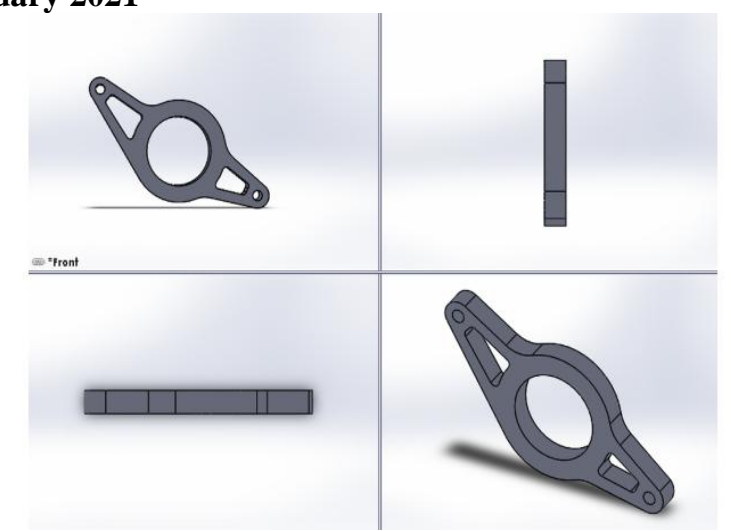

Fig 12: Solid Works model for Iteration 3

A final FEA was performed. This model showed a more efficient distribution of stress and there were lesser regions with extremely low stress. The maximum Equivalent (von-Mises) Stress was $55.097 \mathrm{MPa}$ and the maximum deformation was $0.338 \mathrm{~mm}$ as shown in Fig 13.

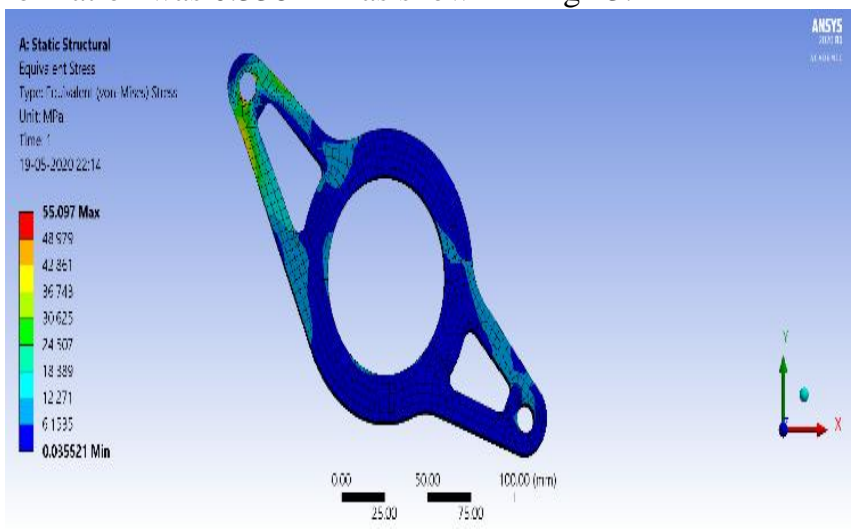

Fig 13: Equivalent Stress Plot for Iteration 3

Vibrational analysis was done once again and the first natural frequency was obtained as $360.37 \mathrm{~Hz}$. Reviewing existing literature for high speed motorbikes which have comparable masses and speeds, the operational frequency is assumed to be around 10 to $25 \mathrm{~Hz}$ for the sprung mass. The first natural frequency of all the designs is considerably higher (above $275 \mathrm{~Hz}$ ). The final iteration has its first natural frequency at $360.37 \mathrm{~Hz}$. There is sufficient gap between the operational frequency and natural frequency of the design. Hence, excessive stresses and deformations due to resonance are successfully avoided.

\section{RESULTS AND DISCUSSION}

The results of the original model as well as the subsequent iterations have been tabulated in Table 2.

Table 2: Comparison of properties for all iterations

\begin{tabular}{|l|l|l|l|l|}
\hline Property & Original & Iteration 1 & Iteration 2 & Iteration 3 \\
\hline $\begin{array}{l}\text { Mass } \\
\text { (gram) }\end{array}$ & 585.143 & 374.069 & 400.964 & 345.826 \\
\hline $\begin{array}{l}\text { Mass } \\
\text { Reductio } \\
\mathrm{n} \\
\text { absolute } \\
(\%)\end{array}$ & 0 & 36.061 & 31.476 & 40.899 \\
\hline $\begin{array}{l}\text { Max } \\
\text { Deformat } \\
\text { ion (mm) }\end{array}$ & 0.112 & 0.213 & 0.329 & 0.338 \\
\hline
\end{tabular}




\section{ISO 9001:2008 Certified}

International Journal of Engineering and Innovative Technology (IJEIT)

Volume 10, Issue 7, January 2021

\begin{tabular}{|l|l|l|l|l|}
\hline $\begin{array}{l}\text { Max } \\
\text { Stress } \\
\text { (Von } \\
\text { Mises) }\end{array}$ & 39.538 & 53.077 & 62.239 & 55.097 \\
\hline $\begin{array}{l}\text { Average } \\
\text { Stress } \\
\text { (MPa) }\end{array}$ & 3.3230 & 6.0461 & 5.6824 & 6.78 \\
\hline $\begin{array}{l}\text { Minimu } \\
\text { m Factor } \\
\text { of Safety }\end{array}$ & 7.082 & 5.275 & 4.499 & 5.082 \\
\hline $\begin{array}{l}\text { First } \\
\text { Natural } \\
\text { Frequenc } \\
\text { y (Hz) }\end{array}$ & 331.34 & 289.46 & 315.36 & 360.37 \\
\hline
\end{tabular}

is no possibility of any unexpected loads being experienced by it. Iteration 2 underwent aggressive material reduction looking at the results of Iteration 1 . However this meant that the maximum stress it experiences is $62.239 \mathrm{MPa}$ which translates to a factor of safety of 4.499 . This was deemed unacceptable as the minimum factor of safety was set at 5.00 to ensure safety of the design. At first glance, a Factor of Safety of 5 seems excessive for a high performance part where material removal is the priority. But, it is well justified when we consider the fact that no physical testing of the design has been done as yet. A lack of real world data along with the extremely high speeds that the pod is designed for means that a higher factor of safety will encompass that uncertainty and ensure safety. Also, the design of this pod is constantly evolving with new components being added, power being increased and layouts being changed. Considering this, a need was felt to make a robust design that can be used even if the weight of the pod increases or a higher top speed is desired which will lead to more forces being applied on the pod. Hence, a self imposed criterion was applied during the design phase and the desired FOS was capped at a minimum of 5 . The deformation of all the iterations is well under $1 \mathrm{~mm}$. So, the fact that iteration 3 suffers maximum deformation $(0.338 \mathrm{~mm})$ is acceptable. The first 20 modes were simulated. However, the latter modes are well above $1000 \mathrm{~Hz}$ and only the first two to three modes must be considered. Figs 18, 19, 20 and 21 show the first mode of the natural frequency of the original design, iteration 1 , iteration 2 and iteration 3 respectively.

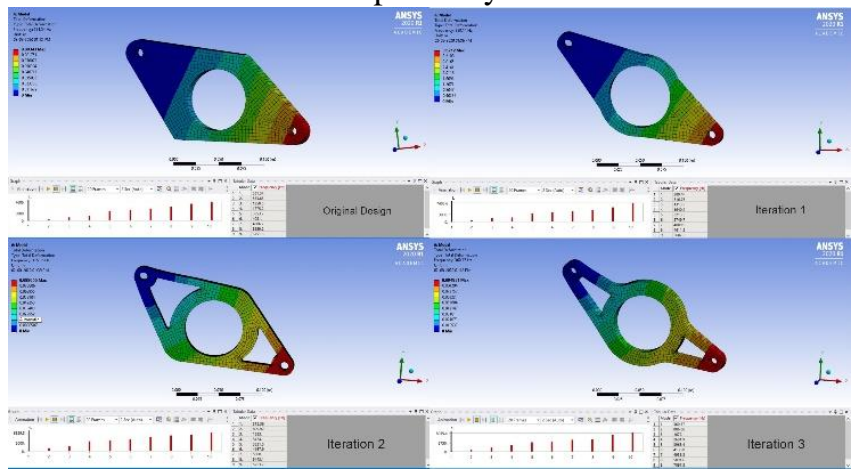

Fig 15: Modal analysis of all four designs

The original design has a natural frequency of $331.34 \mathrm{~Hz}$. This is well beyond the operating frequency of a sprung pod which is always going to be below $40 \mathrm{~Hz}$. Due to the controlled operation of the pod with no unexpected conditions coming into consideration, there is negligible risk of the suspension frequency going above $50 \mathrm{~Hz}$. Hence, from a modal analysis standpoint, no design modifications were deemed necessary since the design was already safe from resonance. Each further iteration was meticulously analyzed and it was ensured that the first mode of the natural frequency was above at least $275 \mathrm{~Hz}$. Iteration 1 returned a result of 289.46 Hz. This was quite a bit lower than the original and not recommended. Iteration 2 had its first natural frequency at 315.36 Hz. Removing materials from the design by cutting the middle portions did not negatively impact the first mode. Iteration 3 had a higher natural frequency than even the 
ISSN: 2277-3754

\section{ISO 9001:2008 Certified \\ International Journal of Engineering and Innovative Technology (IJEIT) \\ Volume 10, Issue 7, January 2021}

original design deeming it the safest because it showed the largest gap between the operating frequency and the natural frequency. Iteration 3 had its first mode at $360.37 \mathrm{~Hz}$.

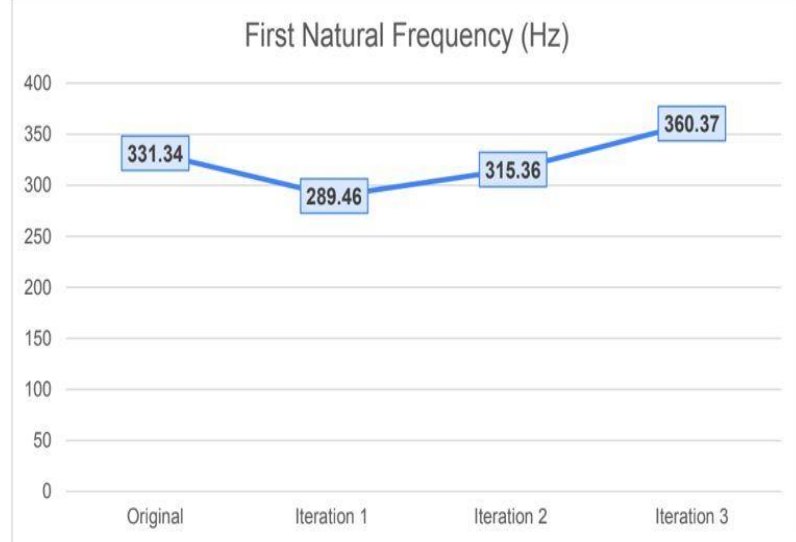

Fig 16: First natural frequencies of subsequent iterations

Iteration 3 has the highest natural frequency and hence is the preferred design from a vibrational analysis criterion. The modal analysis is carried out using an undamped solver. All the modes observed are partial bending and partial torsional modes since the swingarm is free to deform in all planes without any constraints in this analysis. The first mode leans towards bending with minimal torsion observed. However, the higher modes display greater amounts of torsion along with bending. The first natural frequency of the original design as well as all the iterations was well above the operational frequency despite considering all possible kinds of loading. Safety in design being directly proportional to the difference between the operational frequency and the natural frequency of the component under consideration, Iteration 3 was evaluated as the safest. The design has been modeled and analyzed at different stages. The final design is light in weight and provides no difficulty for manufacturing. It is thus better adapted to suit the requirements of a hyperloop pod. A 40 percent mass reduction is achieved over the original design. This comes out to be 239.317 grams. The proposed hyperloop pod will use 8 such swingarms. This means a total saving of $8 * 239.317=1914.536$ grams. Thus, the optimization of this swingarm has resulted in almost a $2 \mathrm{~kg}$ weight reduction. The optimization of each component of the pod chassis in such a manner is expected to cause significant mass reductions and enable the pod to reach greater speeds.

\section{CONCLUSION}

While topology optimization effectively reduces material requirement, it does not compromise the strength of the part designed. This is of prime importance when designing a Hyperloop pod which runs at speeds greater than $50 \mathrm{~m} / \mathrm{s}$. The shape optimization done iteratively reduces stress concentration, maximum deformation and the weight of the component. The factor of safety is maintained at 5. The integration of a connected modal optimization, as outlined in this paper is a powerful tool that will allow positive increase in structural performance. This paper is targeted at improving the performance of the Hyperloop pod and does not focus on significant cost reduction.

\section{REFERENCES}

[1] Bendsøe MP and Kikuchi N., "Generating optimal topologies in structural design using a homogenization method", Computer Methods in Applied Mechanics and Engineering, Volume 71, Issue 2, November, pp: 197-224, 1988.

[2] Bendsøe M., "Optimal shape design as a material distribution problem”, Structural optimization, volume 1, pp: 193-202, 1989.

[3] N. Olhoff, J. Rasmussen, M.P. Bendsøe. "On CAD-Integrated Structural Topology and Design Optimization", Journal of Computer Methods in Applied Mechanics and Engineering, Volume 89, Issues 1-3, August, pp: 259-279, 1991.

[4] S.M. Edmund, R. Arora., "Design optimization of a three-stage transmission using advanced optimization techniques", International Journal of Simulation Multidisplinary Design Optimum, Volume 10, pp: 1-11, 2019.

[5] P. Wu, Q. Ma, Y. Luo, C. Tao., "Topology optimization design of automotive engine bracket", Journal of Energy and Power Engineering, 8(4), pp: 230-235, 2016.

[6] J. Brennan and K. Hayes., "Recent applications of topology and topography optimization in automotive design", Journal of American Institute of Aeronautics and Astronautics, AIAA2000-4709, pp: 1-6, 2012.

[7] Picelli R., Sivapuram R., Townsend S., Kim H.A., "Stress Topology Optimization for Architected Material Using the Level Set Method", Advances in Structural and Multidisciplinary Optimization,pp:1254-1269,2018.

[8] Ballo, Federico and Mastinu, Gianpiero and Gobbi, Massimiliano, "Lightweight Design of a Racing Motorcycle Wheel", SAE 2016 World Congress and Exhibition, pp: 1-7, 2016.

[9] Harald Fredricson. "Structural topology optimization: an application review": International Journal of Vehicle Design, Volume 37, Issue 1, January pp: 1-5, 2005.

[10] KK Ivanovich, KK Konstantinovich. "Suspension System for Hyper Loop", Journal of Transportation systems and Technology, Volume 3, No. 2, pp: 9-10, 2017.

[11] Jain, A., "Design of an Aluminum Alloy Swingarm and its Weight minimization using Topology Optimization", SAE 2015 World Congress \& Exhibition, pp: 1-4, 2015.

[12] Cassani, S. and Mancuso, A., "Shape Optimization of a High Performance Motorbike Single Sided Swingarm", SAE 2005 World Congress \& Exhibition, pp: 1-4, 2005.

[13] Swathikrishnan S, Pranav Singanapalli and A S Prakash. "Design and Analysis of Swingarm for Performance Electric Motorcycle", International Journal of Innovative Technology and Exploring Engineering, Volume-8 Issue-8, pp: 3032-3039, June 2019.

[14] Alessandro Zanarini and Enrico Brugnoni. "Frequency analysis of a motorbike under motion conditions", ISMA2012, Leuven, Belgium, Volume: Multi-Body Dynamics and Control, pp: 2291-2306, 2012. 